\title{
REFINANCIAR DÍVIDAS NADA MAIS É DO QUE POSTERGAR PROBLEMAS
}

Coluna publicada em 3.5.2016: <https://www.conjur.com.br/2016-mai-03/ contas-vista-refinanciar-dividas-nada-postergar-problemas $>$

A situação dos Estados-membros de nossa federação em um cenário de forte crise fiscal e recessão como essa que vivemos é realmente difícil e complexa.

Isto porque nos entes federados predominam as despesas de custeio, em geral de natureza obrigatória, sendo pequena a margem que permite redução. E boa parte das receitas vem de transferências constitucionais, muitas delas oriundas de impostos federais, como o IR e o IPI, que compõem as receitas do Fundo de Participação dos Estados e Distrito Federal, o FPM. Outra parte significativa vem do ICMS, cuja arrecadação guarda estreita relação com a atividade econômica, reduzindo-se quando esta é baixa, como ocorre agora. Sendo assim, vê-se que os Estados têm suas receitas diretamente relacionadas a atos que dependem de ação do governo central, e, em situações como a atual, em que a crise é em boa parte decorrente da má gestão das contas públicas e condução desastrada da política econômica por parte do governo federal, quem sai prejudicado são os Estados.

Ficam, por conseguinte, à mercê de atos sobre os quais não têm ingerência, e veem-se compelidos a administrar o orçamento sem alternativas que possam resolver satisfatoriamente os problemas. Ainda que os governadores consigam melhorar a gestão em seus Estados, os efeitos esperados nem sempre são de curto prazo e não produzem resultados imediatos, além de serem bastante limitados.

Está em discussão, em fase avançada, no Congresso Nacional, o Projeto de Lei Complementar 257/2016, que estabelece o "Plano de Auxílio aos Estados e ao Distrito Federal", ${ }^{1}$ com uma série de medidas voltadas ao "estímulo ao reequilíbrio fiscal", focadas principalmente no refinanciamento das suas dívidas.

1 O projeto foi transformado na Lei Complementar n. 156/2016. 
Uma flexibilização pretendida para a responsabilidade na gestão fiscal, permitindo o alongamento da dívida, não é saudável para as contas públicas, abrindo margem para irresponsabilidades que podem perdurar mesmo após eventual recuperação do crescimento da atividade econômica. E as sucessivas modificaçõos das obrigações financeiras dos Estados da federação podem desestimular a condução de políticas fiscais responsáveis, socializando com a União e os demais entes da federação a má gestão das contas públicas. ${ }^{2}$ De outro lado, a frequência das revisões, em espaços curtos de tempo, torna fracos os vínculos contratuais originais, transmitindo a percepção de que a revisão dos contratos não é uma hipótese excepcional, mas apenas mais uma possibilidade dentre outras diante das dificuldades financeiras, da qual se pode lançar mão com indesejável habitualidade. Este é o problema do risco moral (moral hazard) oferecido pelas constantes modificações dos termos de pagamento da dívida pública em benefício do devedor, que diminuem os incentivos para que se adotem políticas fiscais mais austeras.

Não é fácil.

O federalismo cooperativo é uma boa fórmula de organização do Estado, mas tem suas dificuldades, especialmente em épocas de "vacas magras", pois, como diz a sabedoria popular, "em casa onde falta pão, todos brigam e ninguém tem razão".

Sem pensar no longo prazo, em como tornar os governos mais eficientes, o alívio produzido pelo refinanciamento proposto terá prazo de validade, e daqui a alguns anos, como já ocorreu em outras oportunidades, voltaremos a discutir o problema das finanças estaduais com o mesmo açodamento. O "refresco para os governadores"3 terá efeitos muito breves. O texto da lei complementar precisa ser pensado sem a afobação com que vem sendo discutido, em momento de crise econômica e política que em tudo dificulta a busca de soluçôes mais duradouras para a já velha conhecida dívida dos Estados. "Cautela e caldo de galinha não fazem mal a ninguém” é outro provérbio popular que não deve ser esquecido.

Sempre é bom relembrar o passado para que não se volte a cometer os mesmos erros. Voltamos a falar, afinal, sobre aquilo que muitas vezes já se imaginou assunto encerrado, que se esperava ter sido resolvido com a Lei de Responsabilidade Fiscal. Em 1989, o problema da dívida dos Estados foi enfrentado por meio

2 Uma verdadeira "socialização da gestão fiscal irresponsável", como bem colocado por Rodrigo de Oliveira Faria (Reflexos do endividamento nas relaçôes federativas brasileiras. In: CONTI; SCAFF; BRAGA (Orgs.). Federalismo fiscal: questôes contemporâneas, São Paulo: Conceito Editorial, 2010. especialmente p. 446-450).

3 Como denominado pela Revista Veja, edição 2.471, de 30 de março de 2016, p. 64-65. 
do refinanciamento pela União. A Lei 7.976, de 27 de dezembro daquele ano, concedia novos empréstimos para rolagem, no prazo de 20 anos, dos empréstimos de Estados, Distrito Federal e Municípios perante a União, com a finalidade de assegurar os pagamentos de suas obrigaçōes externas. Em seguida, a Lei 8.727, de 1993, determinou o refinanciamento dos saldos devedores de determinadas obrigações contratadas pelos entes subnacionais junto a órgãos e entidades controlados direta ou indiretamente pela União, o que significou, para os Estados, a possibilidade de renegociar a dívida com as instituições financeiras federais. Em 1995, na Resolução 162, do Conselho Monetário Nacional (CMN), foram criados critérios para a consolidação e o refinanciamento, pela União, das dívidas estaduais e municipais.

Em seguida, os critérios da Resolução 162 serviram para a elaboração do Programa de Apoio à Reestruturação e ao Ajuste Fiscal dos Estados - o PAF, previsto na Lei 9.496, de 11 de setembro de 1997, que autorizava a União a assumir a dívida pública mobiliária e outras obrigações contratuais dos Estados e do Distrito Federal. Mas com a condição do ajuste fiscal, para que os Estados não recorressem a novas renegociações no futuro e fossem capazes de gerar superávits primários, e outras medidas de racionalização da gestão regional, tais como a venda de estatais e a privatização dos bancos estaduais. ${ }^{4}$ Para coroar o controle do endividamento subnacional, veio finalmente a Lei de Responsabilidade Fiscal, com suas previsões de controle do crescimento do endividamento público, em atenção a dispositivos constitucionais relativos às normas gerais de direito financeiro (art. 24, I), especificamente sobre finanças públicas e dívida pública interna e externa (art. 163, I e II). Combinadas com a legislação complementar, foram editadas, em 2001, as Resoluçôes do Senado Federal 40 e 43, que passaram a disciplinar os limites à dívida pública dos Estados, do Distrito Federal e dos Municípios. Nesse contexto, merece destaque um dispositivo legal que traduz o espírito e as expectativas de todas estas transformações, que é o artigo 35 da Lei de Responsabilidade Fiscal: "É vedada a realização de operação de crédito entre um ente da Federação, diretamente ou por intermédio de fundo, autarquia, fundação ou empresa estatal dependente, e outro, inclusive suas entidades da administração indireta, ainda que sob a forma de novação, refinanciamento ou postergação de divida contraída anteriormente." Uma pá de cal na longa tradição de refinanciamentos, pela União, da dívida dos Estados.

4 MORA, Monica; GIAMBIAGI, Fabio. Federalismo e endividamento subnacional: uma discussão sobre a sustentabilidade da dívida estadual. Revista de Economia Política, São Paulo, n. 3, vol. 27, jul.-set. 2007, p. 475. 
E nesse momento de penúria e desespero dos governadores com a situação de caos fiscal cujos efeitos já se fazem sentir, o tema reaparece no citado Projeto de Lei Complementar 257/2016, que traz alterações na Lei de Responsabilidade Fiscal e modifica o regime de refinanciamento que até aqui disciplina as dívidas dos Estados e do Distrito Federal com a União. Prevê-se o alongamento de prazos e a diminuição do valor das prestações a partir de uma série de contrapartidas exigidas dos entes beneficiários, que passam a se valer, para alívio de seu caixa altamente comprometido com despesas de custeio, de uma fórmula simplista, velha e ineficiente: aumentar receitas disponíveis e diminuir gastos sem um objetivo claro de melhor aplicação dos recursos públicos. Este problema de alívio combina-se, ainda, com o aumento da carga tributária, que joga nas costas dos servidores públicos, com um aumento para $14 \%$ da contribuição previdenciária, uma responsabilidade da má gestão das finanças públicas pelas quais não têm responsabilidade.

Nenhuma palavra sobre melhoria da eficiência do gasto! Ou seja: mais do mesmo. Sim, pois melhorar a gestão teria resultados de longo prazo, ao passo que as preocupações emergenciais encaminham medidas de resultados voltadas a produzir efeitos imediatos. Empurram-se os problemas com a barriga, e se perpetua a "administração-bombeiro": apenas voltada a apagar incêndios. Que parece ser o método de administração mais usado há muito tempo em todo o país, sem que nenhuma teoria de administração pública o tenha recomendado. Vê-se, portanto, que temos mais uma medida que vai empurrar e adiar a solução dos problemas, que só vão se agravar e continuar com esse círculo vicioso. Perde-se mais uma oportunidade de promover aperfeiçoamentos na administração pública brasileira, que precisa avançar para "transformar o gestor público naquele agente que conduz a máquina pública pensando para a frente e que um dia deixará de ser o bombeiro que passa a vida a apagar incêndios", como já escrevi nesse espaço (Coluna LDO é instrumento eficiente para a administração pública, publicada em 9 de abril de 2013).

Há ainda outros reparos para os quais convém estar atento. Muitas das medidas previstas no projeto de lei estão cheias de condicionantes que não dependem exclusivamente de atos do Executivo, em uma época de instabilidade política e econômica. Para prolongar por 240 meses (que podem chegar a 360) o prazo de pagamento da dívida e reduzir o montante de cada parcela em $40 \%$ por até 24 meses, os Estados devem se comprometer a restringir as despesas com pessoal, seja pelo corte das despesas mensais totais, seja pela suspensão de qualquer aumento salarial ou criação de novos cargos, com algumas exceçôes para as áreas de educação, saúde e segurança. Exige-se, ainda, a reforma do regime jurídico dos servido- 
res ativos, inativos, civis e militares, o que dependeria da aprovação do Poder Legislativo. Como garantir o cumprimento dos acordos, mesmo após firmados com a União?

Outro defeito grave do projeto tem relação com o Plano Plurianual (PPA). Sem nunca ter sido regulamentado para disciplinar sua finalidade principal, o planejamento orçamentário, o que se propõe no projeto de lei complementar é que tenha uma função voltada apenas a restringir gastos, sem planejar nada. A lei do plano plurianual passaria a prever o limite total da despesa pública primária e outras restriçôes aos gastos com pessoal, e o planejamento de médio prazo, com seus programas e ações, que é sua função principal, continua sem qualquer parâmetro.

Vários artigos de redação confusa e de difícil compreensão só reforçam o açodamento da medida, feita para atender a situação momentânea e dar uma resposta mais uma vez imediata e muito provavelmente ruim, sempre com algumas medidas positivas, para usar a conhecida técnica de misturar o joio com o trigo e dar aparência positiva a mais uma medida com poucas chances de produzir resultados eficazes e definitivos. Muitos assuntos de naturezas diversas em uma mesma lei, contrariando as técnicas legislativas e com potencial de gerar inúmeras dificuldades de interpretação, em prejuízo à segurança jurídica.

Há, ainda, dispositivos de sentido obscuro, que mereceriam cuidadoso debate legislativo, mas que, em meio aos diversos temas tratados pelo projeto de lei complementar, não recebem sua devida atenção. Veja-se o artigo $2^{\circ}$, que dispensa a verificação dos requisitos para a realização de operações de crédito e para a concessão de garantias pela União, inclusive aqueles previstos pela Lei de Responsabilidade Fiscal nos artigos 32 e $40, \$ 2^{\circ}$, caso haja renegociação dos contratos de empréstimos entre as instituições públicas federais e os Estados e o Distrito Federal, com recursos do Banco Nacional de Desenvolvimento Econômico e Social - BNDES. Da mesma forma, propõe-se a inclusão na LRF do artigo 32-A, em cujo $₫ 8^{\circ}$ se dispensa a autorização legislativa para que a União conceda garantias a empresas de natureza financeira por ela controladas, bem como a entidades privadas nacionais e estrangeiras, Estados estrangeiros, agências oficiais de crédito à exportação e organismos financeiros multilaterais quanto às operações de garantia de crédito à exportação, de seguro de crédito à exportação, e de seguro de investimento. Essa flexibilização tão abrangente da autorização legislativa para a concessão de garantias pela União a operaçoos de natureza financeira, dentre outros, evidenciam haver questões que precisam ser mais bem esclarecidas e debatidas.

É interessante notar que a LRF já prevê mecanismos de evitar o descontrole das contas, que, se tivessem sido adequadamente utilizados e fiscalizados, não 
teriam permitido que as coisas chegassem a esse ponto. E agora, descumpridas essas normas, o que se faz é tentar torná-las ainda mais duras - sem obviamente nenhuma garantia de que serão cumpridas, já que não se cumpriram as que estão em vigor. Repete-se a mesma ladainha de sempre. Não se cumprem as normas, e depois são endurecidas - para também não serem cumpridas. Mais do mesmo, como sempre.

O fato é que a sabedoria popular, já mencionada neste texto várias vezes, recomenda uma análise mais cuidadosa desse projeto de lei complementar. Afinal, a pressa é inimiga da perfeição. E quem tem pressa come cru. 